\title{
Atenção a si: da auto-observação à autoprodução
}

\author{
Christian Sade \\ Virginia Kastrup \\ Universidade Federal do Rio de Janeiro
}

\begin{abstract}
Resumo
A atenção é habitualmente investigada como um processo voltado para o mundo exterior. Nos últimos vinte anos tem aumentado nas ciências cognitivas o interesse por metodologias de primeira pessoa para investigar a experiência. A crescente utilização de tais metodologias tem colocado o problema de como acionar e mobilizar uma atenção a si, acessando aquilo que se apresenta como experiência. A partir da abordagem enativa de Francisco Varela, o objetivo do artigo é discutir como a mobilização da atenção a si depende da maneira como ela é corporificada num contexto e situação concreta. Através da abordagem da enação, ampliamos a noção de atenção e concluímos que a atenção a si não se resume a um processo de auto-observação, mas pode constituir um processo de autoprodução.
\end{abstract}

Palavras-chave: cognição; atenção a si; metodologias de primeira pessoa.

\begin{abstract}
Inward attention: from Self-observation to Self-production. Attention is usually investigated as a process toward the outside world. In the last twenty years has increased in the cognitive sciences interest for firstperson methodologies to investigate the experience. The increasing use of such methodologies has placed the problem of how to activate and mobilize inward attention, by accessing what is presented as experience. From the enactive approach of Francisco Varela, the article aims to discuss how the deployment of inward attention depends on how it is embodied in a context and situation. With the enactive approach, we broaden the notion of attention and conclude that attention turned inward is not just a process of self-observation, but may be a process of self-production.
\end{abstract}

Keywords: cognition; inward attention; first-person methodologies.

$\mathrm{A}$ atenção tem sido um tema muito estudado na contemporaneidade. O discurso econômico da produção e da eficiência tem colocado o problema da gestão da atenção como uma questão fundamental para o sucesso profissional. Diante da grande quantidade de informações no contexto contemporâneo, o problema é o direcionamento eficiente da atenção às informações mais importantes e a persistência de modo a transformá-las em ações bem sucedidas, sempre visando sucesso e ganhos futuros (Caliman, 2006; Crary, 1999; Levy, 2004). A difusão crescente do diagnóstico de transtorno de déficit de atenção e hiperatividade (TDAH) também tem contribuído para tornar a atenção um dos principais temas de pesquisa na psicologia e psiquiatria. Caracterizado por comportamento hiperativo, desatenção marcante e impulsividade, o diagnóstico ressalta problemas de atenção que comparecem hoje, sobretudo, nas escolas (Caliman, 2006; Hallowell \& Ratey, 1999; Lima 2004).

O desenvolvimento da psicologia cognitiva a partir da segunda metade do século XX teve na atenção um dos seus tópicos de estudo. Os estudos da psicologia cognitiva sobre a atenção destacaram sua participação na realização de outros processos cognitivos, como o desenvolvimento de habilidades, percepção, lembrança voluntária, coordenação da execução de atividades e experiência consciente. Esses estudos apontam para a atenção como um processo original e irredutível aos demais (Parasuramam, 2000). Tem sido destacado que a atenção não possui conteúdo próprio como a percepção e a memória, por exemplo. Os objetos da atenção seriam os próprios processos cognitivos que ela investe, modula e regula o funcionamento. É assim que Camus (1996) define a atenção como processo responsável pela regulação ou modulação do funcionamento cognitivo.

Em todos esses discursos, tanto o que coloca o problema da gestão da atenção, quanto o que foca o problema do TDAH, como também os estudos da psicologia cognitiva, a atenção investigada tem sido sempre aquela voltada para o mundo, para o meio externo. Nessas investigações o problema da atenção é, em geral, colocado em relação à realização eficiente de tarefas. A atenção está sempre voltada para a busca e captação de informações no mundo com vistas a responder adequadamente a problemas pré-determinados (Kastrup, 2004).

No entanto, recentemente, as ciências cognitivas, que 
habitualmente baseiam suas pesquisas em métodos experimentais de terceira pessoa, têm buscado incluir métodos de primeira pessoa para estudar a experiência (Depraz, Varela, \& Vermersch, 2003, 2006; Jack \& Roepstorff, 2003, 2004; Petitmengin, 2006a, 2006b, 2007, 2009; Thompson, Lutz, \& Cosmelli, 2005; Varela, 1996; Varela, Thompson, \& Rosch, 2003; Vermersch, 1994, 2004). A crescente utilização de metodologias de primeira pessoa tem colocado o problema de como acionar e mobilizar uma atenção a si, acessando aquilo que se apresenta como experiência. Em outras palavras, a investigação da experiência requer uma atenção que se volta para si.

O tema geral do presente artigo é a atenção a si. Analisamos a colocação desse problema nos estudos da cognição assumindo a abordagem enativa, formulada por Francisco Varela. A abordagem da enação afirma que a cognição se caracteriza não pela representação de um mundo prévio por uma mente pré-existente, mas sim pela constituição mútua de si e do mundo através das próprias ações cognitivas, num processo de coemergência (Kastrup, 1999; Varela, 1994; Varela et al., 2003). Tais ações constituem a natureza essencialmente concreta e corporificada da cognição. A atividade de um organismo não é determinada pela informação supostamente captada por ele no ambiente, mas sim pela maneira como ele experimenta a situação, expressa no modo como ele a corporifica.

Sendo assim, o problema que colocamos é: não seria a própria atenção a si mobilizada nas metodologias de primeira pessoa sujeita ao mesmo problema da experiência, isto é, à corporificação da ação e constituição de si? Este é um ponto importante que, a nosso ver, não tem sido ainda devidamente levado em conta pelos autores que têm trabalhado com as metodologias de primeira pessoa. Por exemplo, nas coletâneas organizadas por Antoine Jack e Andreas Roepstorff (2003, 2004) os autores dão grande ênfase à questão da confiabilidade e acurácia das metodologias de primeira pessoa, destacando o problema da falibilidade dos sujeitos ao representar a própria experiência. Para eles a atenção a si está a serviço da autoobservação, no sentido de uma relação representacional por um sujeito (dado) da sua experiência (prévia). Na proposta de entrevista de explicitação (Petitmengin, 2006b; Vermersch, 1994, 2004) o objetivo é explicitar o vivido de referência, isto é, descrever o desenrolar concreto e vivido da ação que realiza uma tarefa real. Essa noção de vivido de referência é formulada dando a impressão de haver um objeto a ser explicitado, como se a experiência a ser investigada e descrita existisse independentemente do ato de conhecê-la. No entanto, como discutiremos adiante, ao descrever a operacionalização da técnica de entrevista de explicitação, os autores apresentam uma modalidade de atenção a si em que se experimenta uma dissolução da separação eu-mundo.

De acordo com nossa análise, os autores que defendem tais metodologias têm sublinhado apenas a atenção a si em sua dimensão de auto-observação, sem destacar a gênese daquilo que nos aparece como um objeto dado, num processo de coemergência. $\mathrm{O}$ que procuraremos ressaltar é que essa auto-observação constitui, ao mesmo tempo, um processo de autoprodução. Enquanto atividade enativa, a atenção não é pilotada por um "eu” ou por uma estrutura cognitiva prévia, nem tampouco possui uma forma natural e universal. Seria mais adequado pensarmos em diferentes modalidades da atenção de acordo com o contexto e a história de acoplamentos. Segundo a abordagem enativa (Maturana \& Varela, 1995; Varela et al., 2003), a compatibilidade que vemos entre o sujeito e o seu meio é resultado, essencialmente, de uma história de mudanças estruturais mútuas, denominada acoplamento estrutural, e não da adaptação a um meio pré-existente. O que descrevemos como regularidades ambientais e cognitivas são frutos de um processo contínuo de codeterminação ou coemergência. Deste modo, para a abordagem enativa, não é possível conceber o objeto como independente do ato de conhecê-lo. Propomos, portanto, uma abordagem do problema da atenção diferente da abordagem padrão da psicologia cognitiva, baseada no paradigma de processamento de informação (Camus, 1996; Parasuramam, 2000). Analisando como a atenção é acionada e mobilizada nas metodologias de primeira pessoa, revela-se o caráter ontológico, e não apenas epistemológico, de tais práticas de pesquisa. Como o próprio Varela buscou afirmar no interior do campo das ciências cognitivas: ser $=$ fazer $=$ conhecer.

\section{O problema da atenção no contexto da psicologia cognitiva}

A atenção é caracterizada por diferentes modalidades. A atenção não é uma entidade única, mas o nome dado para um grupo finito de processos cerebrais que podem interagir, mutuamente e com outros processos cerebrais, desempenho de diferentes tarefas perceptivas, cognitivas e motoras. Segundo Parasuramam (2000) a atenção é responsável pela regulação e modulação do funcionamento dos demais processos cognitivos (percepção, memória, inteligência, etc.). Essa modulação apresenta diferentes aspectos, funções ou variedades da atenção: seleção, vigilância e controle. Mas o que Parasuramam não chega a destacar é que essa descrição de variedades atencionais está diretamente ligada ao contexto das pesquisas, desenvolvidas pela psicologia cognitiva e pelas neurociências. Nesse contexto, os estudos revelam certas preocupações e por isto fazem emergir a seleção, a vigilância e o controle que estão envolvidos na realização de comportamentos dirigidos a metas, voltados para a solução rápida e eficiente de problemas.

Alguns estudos da psicologia cognitiva sobre a atenção tendem a ligar atenção e consciência (Ashcraft, 1994; Camus, 1996). Dessa forma, o par atenção-desatenção se torna tributário do par consciência-não consciência. De fato, a psicologia cognitiva não parece possuir, a nosso ver, uma posição unificadora sobre essa relação entre atenção e consciência. Para Sternberg (2000), por exemplo, atenção e consciência não são sinônimas. Ele define a atenção como o "fenômeno através do qual processamos ativamente uma quantidade limitada de informações do enorme montante de informações disponíveis através de nossos sentidos, de nossas memórias armazenadas e de outros processos cognitivos" (Sternberg, 2000, p. 78). Segundo Sternberg, uma parte desse processamento ativo de informação ocorre sem o nosso conhecimento consciente, daí atenção e consciência não serem a mesma coisa. Posição semelhante possui Anderson, que afirma que "muitos fenômenos da atenção parecem ser inteiramente inconscientes" (Anderson, 
2000, p. 62). Um exemplo fornecido por Anderson é que as pessoas muitas vezes não têm consciência dos pontos para onde moveram seus olhos.

Outros autores enfatizam a ligação entre atenção e recursos ou energia mental. Neste caso, os processos dos quais não somos conscientes são processos ditos automatizados e que se caracterizam justamente por não consumirem recursos atencionais (Ashcraft, 1994; Camus, 1996). Assim, a pessoa não tem consciência dos pontos para os quais ela moveu seus olhos porque essa ação não requer recursos atencionais. Ashcraft afirma: "A atenção, em seu sentido diário e usual, é essencialmente equivalente à capacidade mental consciente ou recursos mentais conscientes. Nós podemos devotar estes recursos atencionais a apenas uma tarefa demandante por vez, ou para duas tarefas simultâneas menos demandantes" (Ashcraft, 1994, p. 134). Os processos cognitivos que exigem o uso de recursos atencionais e envolvem consciência são chamados processos controlados. Muitas das nossas tarefas cotidianas começam como processos controlados e se tornam automáticos. A automatização é importante porque libera recursos atencionais para serem empregados na realização de outras tarefas menos automatizadas, o que é um ganho num ambiente estimulador e que demande muitas tomadas de decisões por parte do sujeito.

O papel da tomada de decisão no funcionamento atencional é enfatizado por Kantowitz, Roediger III e Elmes (2006). Os autores afirmam que as variáveis independentes manipuladas nos experimentos de atenção giram em torno da necessidade do ser humano tomar decisões e do ritmo em que tais decisões podem ser tomadas (na ação automática a "decisão" já está tomada). A manipulação da atenção consiste em aumentar gradualmente as exigências da tarefa até a pessoa se sentir pressionada a acompanhá-las, para responder adequadamente. Quando a resposta exige seleção ou escolha, ela envolve atenção. Por exemplo, aumentando o número de alternativas em uma tarefa de reação com escolha, aumenta-se o número de decisões que precisam ser tomadas para identificar o estímulo correto e selecionar a resposta associada. Segundo Kantowitz et al. (2006), a variável dependente normalmente estudada nos experimentos é o tempo de reação e o número de acertos e erros. Como afirma Sternberg (2000), a atenção realça os estímulos que nos interessam, ampliando a probabilidade de que possamos responder rápida e corretamente a eles.

A atenção estudada está essencialmente voltada para a realização de tarefas, para a manutenção e consecução de comportamentos dirigidos a metas, como sublinha Parasuramam (2000). Ela está fundamentalmente voltada para o processamento de estímulos e apreensão de informações que interessam ao sujeito para responder de forma adequada ao mundo. De acordo com Kastrup (2004) a atenção tematizada nas discussões sobre o transtorno do déficit de atenção e hiperatividade (TDAH) também é sempre uma atenção como processo instrumental ou subsidiário à solução de problemas pré-determinados. É preciso ressaltar que a atenção avaliada é sempre voltada para objetos e estímulos do mundo externo, ou seja, para a captação e busca de informações. É certo que esta atenção estudada nos experimentos de psicologia cognitiva constitui grande parte de nossa atenção cotidiana. Mas existem outros problemas, como aquele da atenção a si, que também exigem investigação.

Outra limitação de muitos estudos é reduzir o funcionamento atencional a um problema biológico, como o faz Alan Baddeley (1998) ao apresentar uma concepção evolutiva e funcional da consciência. Numa outra direção, Jonathan Crary (1999) propõe uma genealogia da atenção apontando como essa atenção instrumental tornou-se um valor a partir do final do século XIX. Segundo Crary (1999) sua importância está diretamente ligada ao surgimento de um campo social, urbano, psíquico e industrial cada vez mais saturado de informações sensoriais. $\mathrm{O}$ sistema econômico emergente demanda a atenção do sujeito a uma ampla gama de novas tarefas produtivas e espetaculares. Assim, parte da lógica cultural do capitalismo exigia que aceitássemos como natural a mudança rápida da nossa atenção de uma coisa para a outra. Por outro lado e ao mesmo tempo, essa lógica de troca e circulação acelerada de produtos minava a base de uma atenção disciplinada, resultando num regime no qual a atenção e a distração revelam-se indissociáveis. Ou seja, a atenção instrumental e a distração surgem ao mesmo tempo como problemas, requerendo novos métodos para administrar e regular a percepção. Isto significa que a atenção já surge como um objeto problemático para a então nascente psicologia experimental, que passa a buscar as condições de sua eficiência. A análise histórica feita por Crary (1999) aponta para a ligação entre a atenção estudada nos laboratórios de psicologia e o contexto social de uma época. Dessa forma, pode-se com segurança supor que outras práticas, em outros contextos, poderão produzir diferentes modalidades atencionais.

Destacadas a partir da década de 90, as metodologias de primeira pessoa põem em cena modalidades atencionais distintas daquelas mobilizadas e tematizadas pelos experimentos de psicologia cognitiva. O ponto de partida é a própria concepção de uma atenção a si, diferente da atenção voltada para a apreensão de informações externas (Depraz et al., 2003; Petitmengin, 2007; Thompson et al., 2005). A questão a ser destacada é a mobilização de uma atenção à experiência pré-refletida (Varela \& Shear, 1999). Outro ponto é colocação do problema de uma atenção panorâmica e aberta (Depraz et al., 2003, 2006; Petitmengin, 2006a, 2007), que guarda semelhança com a atenção flutuante descrita por Freud (1912/1969) no contexto da clínica psicanalítica.

As metodologias de primeira pessoa são procedimentos disciplinados para que o sujeito possa acessar e descrever a sua própria experiência (Thompson et al., 2005; Varela \& Shear, 1999). Uma questão que se coloca é que não se trata de realizar um simples procedimento de auto-observação ou uma descrição do que espontaneamente vem à cabeça do sujeito, ou daquilo que lhe é imediatamente consciente. Daí o problema metodológico: como a atenção a si se torna atenção à experiência? Pierre Vermersch $(1994 ;$ 2004) e Claire Petitmengin (2006a, 2006b) ressaltam o problema paradoxal de como a familiaridade com nossa experiência (como se ela fosse evidente para nós) nos torna cegos para muitos de seus aspectos pré-refletidos. Esses aspectos não são notados pela nossa consciência imediata do dia a dia, mas são visados pelas investigações de primeira pessoa. Eles podem ser acessados pela atenção a si porque também não são definitivamente inconscientes. O emprego dessa atenção que 
se volta para si, ou seja, para a própria experiência, é contrahabitual. Dessa forma, trabalhos como os de Petitmengin (2006a, 2006b, 2007), Vermersch (1994, 2004), Jack e Roepstorff (2003, 2004), Depraz et al. (2003, 2006), Thompson et al. (2005), revelam certas operações sobre a atenção, que são necessárias para se apreender essa dimensão pré-refletida da experiência. Vejamos como a atenção é apresentada em algumas pesquisas baseadas na abordagem da enação que utilizam metodologias de primeira pessoa. Inicialmente, apresentamos uma pesquisa que mostra como o cultivo de certo tipo de atenção a si permite a ampliação do campo de consciência. Em seguida, veremos a atenção a si na fenomenologia pragmática e por fim na entrevista de explicitação.

\section{Atenção a si e ampliação do campo de consciência}

Uma pesquisa feita por Slagter et al. (2007) buscou investigar os efeitos de três meses de intensiva meditação Vipassana sobre a distribuição de recursos atencionais que são normalmente limitados. Segundo os autores, uma das maiores dificuldades do sistema atencional é processar dois estímulos relevantes temporalmente próximos. Quando o segundo estímulo é apresentado num intervalo de apenas meio segundo após o primeiro, ele frequentemente não é detectado. Isso é chamado déficit da "piscada atencional" (attentional-blink), e considerase que ele resulta da competição entre dois estímulos frente a recursos atencionais limitados.

A pesquisa investigou os efeitos de meditação intensa sobre os resultados comportamentais e cerebrais da realização de tarefas dessa natureza. A meditação Vipassana é uma prática de atenção a si que cultiva uma atenção básica (bare attention), isto é, uma forma de awareness sensorial não reativa. "Esta forma de atenção é não reativa no sentido em que, idealmente, alguém não se torna fixado em julgamentos e respostas afetivas aos estímulos sensoriais e mentais" (Slagter et al., 2007, p. 1228). Com tal prática de atenção a si, o sujeito é capacitado a se fixar menos em um único estímulo, isto é, ele pode aprender a alocar aí menos recursos. Após três meses de prática de meditação, os resultados da pesquisa mostraram que a atenção tornou-se menos capturada pelo primeiro estímulo, o que resultou num menor efeito de "piscada atencional", sem comprometer a detecção do primeiro estímulo. Esta menor alocação de recursos no primeiro estímulo, isto é, a menor fixação sobre ele, também foi detectada pela análise da resposta cerebral correspondente.

Tal pesquisa parece deixar claro como o cultivo da atenção básica, oriunda das tradições orientais de meditação, permite ao sujeito corporificar uma atitude atencional mais receptiva, caracterizada por uma menor prontidão para responder aos estímulos, como normalmente é demandado no contexto social, revelando outras formas de atenção que aquelas estudadas nos experimentos da psicologia cognitiva. Além disso, o cultivo da atenção básica permite uma ampliação do campo de consciência. "Atenção básica é a clara e determinada awareness do que verdadeiramente acontece para nós e em nós, nos momentos sucessivos da percepção. (....) sem reagir a eles" (Schwartz, 1999, p. 296) - de modo a incluir elementos que, sob condições de maior responsividade, não seriam conscientes ${ }^{1}$.

\section{Atenção a si na fenomenologia pragmática}

Varela (1996) encontra na redução fenomenológica um método sistemático para explorar de forma disciplinada a experiência. Para isto, propõe um uso da redução no interior das ciências cognitivas como uma fonte de dados empíricos de primeira pessoa. Isso implica investir na fenomenologia como uma prática, possível de ser operada por um agente concreto numa situação de pesquisa. Depraz et al. $(2003,2006)$ afirmam que Husserl não abordou a redução como um método concreto, nem ressaltou as dificuldades e obstáculos na sua realização (como faz, por exemplo, o budismo com a meditação). É isso que Depraz et al. $(2003,2006)$ buscam com a proposta de uma fenomenologia pragmática. Eles buscam descrever como o método da redução é corporificado por um sujeito, ao invés de ser apenas uma interpretação ou compreensão teórica do trabalho de Husserl. Afirmam:

A fenomenologia reivindicada aqui se caracteriza por seu funcionamento concreto, sua dimensão operatória, processual ou performativa, logo, sua práxis, muito mais do que por sua sistemática teórica interna, sua visada de conhecimento e de justificação a priori e apodíctica dos conhecimentos (Depraz et al., 2006, p. 77).

A abordagem pragmática da redução visa à redução não apenas como um método para se explorar a experiência, mas, como sendo sua própria práxis, ela mesma, uma experiência. Ao se operar a redução, essa experiência se apresenta como um processo de devir da consciência. É no interior dessa questão do devir consciente - "retomar as diferentes etapas do processo pelo qual advém à minha consciência clara alguma coisa de mim mesmo que me habitava de modo confuso e opaco, afetivo, imanente, logo, pré-refletido" (Depraz et al., 2006, p. 77) - que os autores descreverão a prática da redução.

Deprazn et al. $(2003,2006)$ fornecem uma estrutura geral do processo de tomada de consciência. Essa estrutura descreve o próprio gesto de redução, que é chamado ciclo básico e é constituída por três fases entrecruzadas. A primeira é uma etapa de suspensão da atitude natural, atitude judicativa com a qual normalmente nos voltamos para o mundo, e que caracteriza uma atitude de controle. A segunda é uma etapa de redireção da atenção do "exterior" para o "interior”. E há uma terceira etapa de mudança da qualidade da atenção, de acolhimento da experiência, chamada "deixar-vir" (lacher prise). O uso da redução para investigar a experiência requer uma incorporação dessas três fases. Tais gestos são contraintuitivos, ou seja, eles sofrem resistência de nossa consciência cotidiana, marcada pela atitude natural. Sendo assim, podemos afirmar que a prática da redução possui efeitos constitutivos de si. Depraz et al. afirmam: "Husserl permanece ligado à busca pelo conhecimento e não produz uma ética como tal, entretanto, a ênfase na atitude de suspensão pode ser interpretada como um ethos geral da vida e conhecimento" (Depraz et al., 2003, p. 26).

A suspensão e a redireção da atenção pressupõem a saída de uma posição de controle, mais voltada para o agir e a vida prática. Elas podem ser acionadas espontaneamente, por exemplo, no encontro com uma obra de arte. $\mathrm{Na}$ atitude natural 
nossa atenção está voltada para a vida prática. Ela se engaja na percepção dos outros, na apreensão de informações provenientes do mundo, na busca de objetivos. Como afirmam Depraz et al. (2003, 2006), a atenção é naturalmente interessada no mundo, ela não se desvia dele espontaneamente de forma alguma, pois o efeito de captação é irresistível. A atenção direcionada para si e desviada ou desinteressada do mundo, é muito inabitual, na medida em que há relativamente poucas ocasiões de exercê-la espontaneamente ou em resposta a uma demanda educativa. Para o iniciante na prática de meditação ${ }^{2}$ é preciso suspender o investimento no agir. Esse não agir é, no princípio, literal, isto é, permanecer em uma posição sentada, em uma atitude de escuta atenta. É por isso que, segundo Depraz et al. (2003, 2006), essa ênfase na ideia de suspensão da atitude de controle conduz ao uso de uma linguagem que é aquela do relaxamento, da entrega ou do deixar-vir.

A redireção da atenção não visa pensamentos ou imagens internas, mas se volta para a fonte dos processos mentais, para o que está emergindo como objeto/conteúdo, e não para o objeto em si. Não se trata de atentar para a primeira coisa que vem à cabeça, ou aquilo que é imediatamente consciente. De acordo com Depraz et al. (2003; 2006), Husserl concebe essa redireção ou conversão da atenção como uma mudança de atitude na relação com o mundo, no sentido de uma conversão do interesse natural dedicado ao objeto, em direção ao ato que me permite acessá-lo. O movimento da redução fenomenológica é a conversão do objeto ao ato, da coisa (quod) ao modo dela (quomodo). Já a mudança da qualidade da atenção e a atitude de “deixar vir" são definidas pela manutenção da tensão entre um ato de atenção sustentada e um não preenchimento imediato. Há uma espera sem conhecimento do conteúdo que vai se revelar, ou seja, uma espera não focalizada e por isso aberta, normalmente descrita como destituída de qualquer discriminação imediata, como "não há nada", "é uma névoa", "é confuso".

\section{Atenção a si na entrevista de explicitação}

Os trabalhos de Vermersch $(1994,2004)$ e Petitmengin (2006a, 2006b) são voltados para técnicas de entrevista e, neste sentido, mobilizam uma segunda pessoa que possibilita o acesso a dados de primeira pessoa. A entrevista pode auxiliar ou conduzir um sujeito não treinado à tomada de consciência dessa dimensão pré-refletida da experiência. Vermersch ressalta como um entrevistador perito pode conduzir e capacitar o entrevistado a tornar-se consciente de sua experiência subjetiva e descrevêla. Petitmengin afirma que o entrevistador deve guiar o sujeito de modo que este acione certos "gestos interiores": estabilizar a atenção, mudar a direção da atenção do o quê para o como, conduzi-la através de diferentes estratos da experiência, adotar uma posição específica de atenção que é diferente do nosso modo usual de estar atento: atenção panorâmica, periférica, difusa, não sensorialmente determinada, e sensível às descontinuidades as mais sutis. A discussão desdobra e aprofunda o estudo do ciclo básico apresentado por Depraz et al. (2003).

Segundo Petitmengin (2006a, 2006b), em geral o entrevistado não tem acesso direto às diferentes dimensões e aspectos da experiência. O problema para conduzi-lo no acesso a elas é a configuração de uma particular posição atencional, a qual permite acessar o que ela denomina fonte do pensamento (Petitmengin, 2007). Nessa dimensão da experiência imagens e emoções não possuem contornos claros e os diferentes planos se entrecruzam numa base comum a partir da qual elas emergirão. Sob nossos pensamentos e imagens constituídos, dos quais possuímos uma consciência imediata e refletida, se encontram gestos e micromovimentos, bem como uma experiência transmodal. Petitmengin (2006a, 2007) afirma que para percebermos, memorizarmos, imaginarmos, realizamos ordinariamente, de modo inteiramente pré-refletido, um conjunto de gestos sutis, como transformações da direção da atenção, da intensidade e do campo de atenção, modificações da posição de percepção (alocentrada ou egocentrada), apreciação, comparação, gestos interiores de alinhamento, de abertura, de contração, de separação e identificação. Essas microatividades dão uma qualidade dinâmica à experiência, e são elas que fazem emergir a própria relação sujeito-objeto. Petitmengin afirma ainda que essa fonte é transmodal, isto é, ela não é específica a nenhum registro sensorial, trata-se mais de uma sensação indistinta e embaçada, que pode ser correlacionada a diferentes modalidades sensoriais.

Para Petitmengin (2006a, 2006b, 2007) a tomada de consciência dessa fonte do pensamento, que é pré-refletida, supõe a adoção de um tipo especial de "posição de atenção", diferente do modo usual de estar atento (attentiveness). Tal modo especial de atenção é definido por três características: ausência de modalidade sensorial específica, em termos de seu alvo ela é panorâmica e difusa, e possui um caráter receptivo. $O$ fato dessa atenção não estar relacionada a um registro sensorial específico faz com que ela se pareça a uma "atitude de expectativa", não sensorialmente determinada. Petitmengin (2007) lembra um exemplo de William James. Se você diz “espere!" “olhe!” nossa consciência é lançada numa atitude de expectativa, embora nenhum objeto esteja diante dela.

Essa atenção é marcada por uma abertura, o que é importante tendo em vista que o contato com essa dimensão muito fina e dinâmica da experiência pré-refletida, marcada por descontinuidades sutis, requer uma modalidade de atenção difusa, panorâmica, periférica ou flutuante (Petitmengin, 2006a; 2007). Essa atenção panorâmica é diferente da atenção focada, que é concentrada sobre um conteúdo particular. A não focalização dá a essa atenção uma abertura que lhe permite entrar em contato com elementos e aspectos indefinidos da nossa experiência.

É importante a questão apontada por Petitmengin (2007) de que a atenção a essa dimensão da experiência não constitui um campo de consciência do tipo foco/margem. Petitmengin afirma que essa dimensão não deve ser confundida com o "plano de fundo" (o "horizonte", a "margem") de uma percepção. Em certas concepções da atenção e da consciência, quando focamos nossa atenção sobre um dado objeto ele é simultaneamente posicionado sobre um plano de fundo indistinto (formas e cores indistintas). Nós precisamos apenas direcionar nossa atenção para outro elemento neste plano de fundo para percebê-lo distintamente, configurando outro campo foco/margem. Mas, segundo Petitmengin, mesmo quando alguém direciona a atenção para essa experiência pré-refletida (fonte do pensamento) ela 
permanece indistinta. Tal indistinção está ligada ao fato de que ela não é constituída por formas circunscritas.

A suspensão da atitude de busca de informação enseja uma atitude receptiva que caracteriza essa atenção a si. Um ethos marcado pela abertura ao encontro de algo que não se buscava (Depraz et al., 2003, 2006; Petitmengin, 2007). Como diz Petitmengin (2007), não se trata de voltar-se com esforço em direção à fonte do pensamento para apreendê-la, mas, sim de tornar-se disponível para ela, de permitir-se ser impregnado por ela, ou estar em sintonia com ela. O trabalho do entrevistador é conduzir o entrevistado de modo que ele não se esforce para evocar a experiência, mas que a deixe vir.

Investigar a atenção a si como atenção a essa experiência transmodal e pré-refletida é investir no domínio da sensibilidade, em contraposição ao engajamento no agir, típico da atitude de controle e da atenção voltada para a realização de tarefas. É a partir dessa suspensão que o contato com a experiência ganha esse sentido de encontro, de receptividade, de ausência de controle. "Ver não é lançar o seu olhar em direção a alguma coisa, projetando-a, agarrando-a, mas realmente é deixar a coisa se imprimir em você. Você é completamente passivo, e você deixa a cor, a paisagem, vir até você", trecho de entrevista citado por Petitmengin (2007, p. 62). A suspensão da atitude de controle implica uma mudança nas condições da atenção, em que habitualmente o sujeito se coloca como piloto do processo de atenção. Na presente situação, o sujeito não se sente agente ou proprietário do conteúdo que virá preenchê-la. É por isso que uma das características dessa dimensão dinâmica e pré-refletida da experiência, segundo Petitmengin (2006a; 2007), é o sentimento de perda de identidade e da fronteira interno-externo. "A pessoa descrevendo a experiência não diz 'eu tenho uma ideia, eu vejo uma imagem', porém, 'uma imagem me vem, uma imagem me aparece"” (Petitmengin, 2006a, p. 89).

\section{A atenção a si como atividade enativa}

A partir da abordagem da enação, estudos que utilizam metodologias de primeira pessoa mobilizam e discutem novas formas de atenção, nos convidando a reavaliar e, sobretudo, a ampliar a concepção de atenção que tem até agora sido dominante na psicologia cognitiva. Entendida como uma atividade enativa, a atenção não cabe no modelo do processamento de informação. É necessário investigar diferentes modalidades da atenção que surgem de acordo com o contexto e uma história de interações, marcada por mudanças estruturais mútuas. Entendido do ponto de vista da enação, o problema da atenção a si abre um novo e fecundo campo de pesquisa, revelando diferentes formas de corporificação. Essa ampliação da discussão sobre o processo de atenção pode ter relevantes implicações, tendo em vista a importância do tema da atenção no contemporâneo, convidando a uma nova abordagem de problemas como a gestão da atenção e TDAH. Tais análises convidam também a refletir sobre os avanços que podem ser trazidos pelas metodologias de primeira pessoa.

Maturana e Varela (1995) afirmam que todo conhecer humano pertence a um mundo próprio, é vivido dentro de uma tradição cultural (como é a própria tradição científica). Ao tentar conhecer o conhecer, acabamos por nos encontrar com nosso próprio ser. Destacamos aqui, por meio das metodologias de primeira pessoa, que ao investigarmos dimensões da experiência, menos acessíveis a nós mesmos e pouco presentes nos estudos tradicionais, encontramos relações e ações que nos constituem, dos quais advém o si e o mundo, mas, para os quais normalmente somos "cegos". Ao mesmo tempo, somos levados a reconhecer que toda prática cognitiva, inclusive as práticas científicas, são inseparáveis de sua enação ou incorporação, de uma experiência de sentir e agir, e de uma história de acoplamentos estruturais em que sujeito e objeto são inseparáveis.

Nesse sentido, a discussão sobre metodologias de primeira pessoa, tal como sobre toda atividade de conhecimento, não é apenas epistemológica, mas sobretudo ontológica. A atenção mobilizada e analisada nos experimentos de psicologia cognitiva ou nas metodologias de primeira pessoa está relacionada à produção de regimes cognitivos tanto para o sujeito da pesquisa quanto para o cientista. Ela é inseparável da constituição de um ethos, de uma atitude atencional e existencial, ou seja, de uma experiência de si e de mundo. Nas pesquisas aqui analisadas, a investigação da experiência levou o sujeito a sair de uma posição de agente e proprietário da experiência. Isso é muito diferente do que se passa nos laboratórios de psicologia cognitiva, onde se aciona uma atenção instrumental para a solução de problemas pré-determinados. As metodologias de primeira pessoa ensejam a própria enação no processo de atenção a si, diferente daquela habitualmente mobilizada no nosso dia a dia. Tanto na fenomenologia pragmática quanto na entrevista de explicitação, o acesso à experiência depende da atualização de uma atitude atencional de abertura para uma experiência que se apresenta como fonte de virtualidades da subjetividade, mais do que voltada para conteúdos objetivos. Nessa posição atencional o sujeito experimenta a dissolução da separação eu-mundo e um ethos marcado pela receptividade.

Habitualmente o sujeito não está consciente de como procede para realizar uma ação. Quando nossa atenção está concentrada numa dada atividade, somos absorvidos pelos objetivos, pelo o quê, e pouco sabemos dos processos internos pelos quais tentamos alcançar tais objetivos - o como. Em geral, só conhecemos os objetivos e resultados alcançados, num enquadramento operacional e social da ação. Segundo Vermersch (1994), esta inconsciência não é uma condição natural, mas fruto de nossa formação, mais fundamentalmente voltada para os resultados a serem atingidos do que para os procedimentos concretos e vividos que realizamos. Podemos dizer que isso está ligado ao valor que a atenção instrumental ganhou em nosso contexto social. Dito de outra forma, nós não somos formados para voltar a nossa atenção para os meios e processos dos quais lançamos mão, apenas para os resultados e a eficiência da atividade cognitiva. Nesse sentido, as práticas de estudo da atenção empreendidas a partir da abordagem da enação ajudam a entender que estudar a experiência não é abordar uma realidade cognitiva até então oculta e desconhecida, a ser desvelada por meio de práticas adequadas de atenção a si. A atenção em geral, e a atenção a si em particular, está ligada a um contexto e a uma história, e, sobretudo, a uma constituição de si. Essa questão não chega a ser ressaltada pelos autores que discutem as metodologias de primeira pessoa. Não recusamos 
o conhecimento sobre a atenção produzido pela psicologia cognitiva tradicional, mas somos obrigados a reconhecer seus limites, que não dizem respeito apenas aos temas estudados, mas a sua suposta neutralidade na busca de mecanismos universais e abstratos (Silva et al., 2010). Nesta medida, a abordagem enativa da atenção é um convite a enfrentar novos problemas e reconhecer que sempre estamos em vias de atualizar e mesmo de produzir certas práticas de atenção. Isto vale para a atenção dos sujeitos e dos próprios cientistas, ambos encarnando formas de atenção concretas, indissociáveis de questões ético-políticas.

\section{Referências}

Anderson, J. R. (2000). Psicologia Cognitiva e suas implicações experimentais. Rio de Janeiro: LTC..

Ashcraft, M. H. (1994). Human memory and cognition. New York: Harper Collins College Publishers.

Baddeley, A. (1998). Memória humana: teoria e prática. Madri: McGraw-Hill.

Calimam, L. (2006). A biologia moral da atenção: a constituição do sujeito (des) atento (Tese de doutorado não publicada). Universidade do Estado do Rio de Janeiro, Rio de Janeiro).

Camus, J-F. (1996). La psychologie cognitive de l'attention. Paris: Armand Colin.

Crary, J. (1999). Suspensions of perception: attention, spectacle, and modern culture. Cambridge: MIT Press.

Depraz, N., Varela, F., \& Vermersch, P. (2003). On becoming aware. Philadelphia: John Benjamins Publishing Company.

Depraz, N., Varela, F., \& Vermersch, P. (2006). A redução à prova da experiência. Arquivos Brasileiros de Psicologia, 58(1), 75-86.

Freud, S. (1969). Recomendações aos médicos que exercem a psicanálise. In S. Freud (Org.), Obras completas de Sigmund Freud (vol. 12, pp. 122-133). Rio de Janeiro: Imago (obra originalmente publicada em 1912).

Hallowell, E., \& Ratey, J. (1999). Tendência à distração: identificação e gerência do distúrbio do déficit de atenção (DDA) da infância à vida adulta. Rio de Janeiro: Rocco.

Jack, A., \& Roepstorff, A. (2003). Why trust the subject? Journal of Consciousness Studies, 10(9-10), 5-20.

Jack, A., \& Roepstorff, A. (2004). Trust or interaction? Journal of Consciousness Studies, 11(7-8), 5-22.

Kantowitz, B. H., Roediger III, H., \& Elmes, D. (2006). Psicologia experimental. São Paulo: Thomson Learning.

Kastrup, V. (1999). A invenção de si e do mundo. Campinas: Papirus.

Kastrup, V. (2004). A aprendizagem da atenção na cognição inventiva. Psicologia e Sociedade, 16(3), 7-16.

Levy, P. (2004). O ciberespaço e a economia da atenção. In A. Parente (Org.),
Tramas da rede (pp. 174-188). Porto Alegre: Sulina.

Lima, R. C. (2004). A construção contemporânea de bioidentidades: um estudo sobre o transtorno de déficit de atenção/hiperatividade (TDA/H) (Dissertação de Mestrado não publicada). Universidade do Estado do Rio de Janeiro, Rio de Janeiro.

Maturana, H., \& Varela, F. (1995). A árvore do conhecimento. Campinas: Editorial Psy.

Parasuramam, R. (2000) The attentive brain: issues and prospects. In R. Parasuramam (Org.), The Attentive Brain (pp. 5-20). Cambridge: MIT Press.

Petitmengin, C. (2006a). L'énaction comme experience vécue. Intellectica, 43, 85-92.

Petitmengin, C. (2006b). Describing one's subjective experience in the second person: an interview method for the science of consciousness. Phenomenology and the Cognitive Sciences, 5, 229-269.

Petitmengin, C. (2007). Towards the source of thoughts: the gestural and transmodal dimension of lived experience. Journal of Consciousness Studies, 14(3), 54-82.

Petitmengin, C. (2009). Ten years of viewing from within: the legacy of Francisco Varela. Exeter: Imprint Academic.

Schwartz, J. (1999). Mental force and the advertence of bare attention. Journal of Consciousness Studies, 6(2-3), 293-296.

Silva, A. E., Passos, E., Fernandes, C. V., Guia, F. R., Lima, F. R., Carvalho, J. F., Barros, L. R., \& Vasconcelos, C. S. (2010). Estratégias de pesquisa no estudo da cognição: o caso das falsas lembranças. Psicologia \& Sociedade, 22(1), 84-94

Slagter, H., Lutz, A., Greischar, L., Francis, A., Nieuwenhuis, S., Davis, J., \& Davidson, R. (2007). Mental training affects distribution of limited brain resources. PLoS Biol, 5(6), 1228-1235.

Sternberg, R. J. (2000). Psicologia cognitiva. Porto Alegre: Artmed.

Thompson, E., Lutz, A., \& Cosmelli, D. (2005). Neurophenomenology: an introduction for neurophilosophers. In A. Brook \& K. Akins (Orgs.), Cognition and the brain: the philosophy and neuroscience movement (pp. 40-97). Cambridge: Cambridge University Press.

Varela, F. (1994). Conhecer: as ciências cognitivas tendências e perspectivas. Lisboa: Instituto Piaget.

Varela, F. (1996). Neurophenomenology: a methodological remedy for the hard problem. Journal of Consciousness Studies, 3(4), 330-349.

Varela, F., \& Shear, J. (1999). First-person accounts: why, what, and how. Journal of Consciousness Studies, 6(2-3), 1-14.

Varela, F., Thompson, E., \& Rosch, E. (2003). A mente incorporada: ciências cognitivas e experiência humana. Porto Alegre: Artmed.

Vermersch, P. (1994). L'entretien d'explicitation. Issy-les-Moulineaux: ESF Éditeur.

Vermersch, P. (2004). Prende en compte la phénoménalité. Expliciter, 57, 35-46. 
1. Schwartz (1999) defende o cultivo e uso dessa atenção básica para o tratamento de pacientes com desordem obsessivocompulsiva. A proposta é que com a atenção básica os pacientes possam mudar a direção de sua atenção de modo a evitar os pensamentos e respostas mentais incômodas que caracterizam a desordem.

2. Depraz, Varela e Vermersch (2003) apresentam exemplos de outras práticas em que é realizado o devir consciente: introspecção guiada (entrevista de explicitação), Shamatha (sessão de meditação), visão estereoscópica, oração do coração (tradição ortodoxa), sessão de psicanálise, sessão de escrita, início de curso de filosofia.

Christian Sade é doutor em Psicologia pela Universidade Federal do Rio de Janeiro. Endereço para correspondência: Rua Joaquim Távora, 213/302, Icaraí, Niterói/RJ. CEP: 24230-541. Tels.: (21)26114951/9535-5550. E-mail: christiansadevas@yahoo.com.br

Virgínia Kastrup, doutora em Psicologia Clínica pela Pontifícia Universidade Católica de São Paulo, pósdoutora em Ciências da Cognição no Centre National de la Recherche Scientifique (Paris), e em Psicologia Cognitiva da deficiência visual no Conservatoire National des Arts et Metiers (Paris), é professora Associada na Universidade Federal do Rio de Janeiro. E-mail: virginia.kastrup@gmail.com 